\title{
Respostas fisiológicas de sementes e plântulas de alface submetidas ao extrato de Philodendron bipinnatifidum ${ }^{1}$
}

\section{Physiological responses of seeds and seedlings of lettuce submitted to Philodendron bipinnatifidum extract ${ }^{1}$}

\author{
Tiago Zanatta Aumonde ${ }^{2 *}$; Emanuela Garbin Martinazzo ${ }^{3}$; Tiago Pedó4; \\ Junior Borella ${ }^{4}$; Luciano do Amarante \\ Francisco Amaral Villela ${ }^{2}$; Dario Munt de Moraes $^{5}$
}

\section{Resumo}

O trabalho foi conduzido com o objetivo de avaliar o efeito de diferentes concentrações do extrato de Philodendron bipinnatifidum Schott. sobre o desempenho germinativo e o metabolismo enzimático de sementes e plântulas de alface. Os tratamentos foram extratos de folhas maduras nas concentrações 0; $6 ; 12 ; 25$ e 50\%. Foram avaliados a germinação, primeira contagem de germinação, velocidade e índice de velocidade de germinação, comprimento de parte aérea e raiz primária, massa seca total de plântulas, condutividade elétrica, teores de clorofila, atividade das enzimas $\alpha$-amilase, superóxido-dismutase, catalase e ascorbarto peroxidase, peroxidação de lipídica, teor de peróxido de hidrogênio e emergência de plântulas, comprimento de parte aérea e da raiz primária e massa seca total das plântulas emergidas. Houve redução da germinação, do índice de velocidade de germinação e da massa seca ao incrementar a concentração do extrato. $O$ teor de peróxido de hidrogênio, a peroxidação de lipídica e a atividade das enzimas superóxido-dismutase, catalase e ascorbarto peroxidase aumentaram com a concentração. $\mathrm{O}$ aumento da concentração do extrato de folhas de $P$. bipinnatifidum afeta negativamente a atividade da enzima $\alpha$-amilase e provoca elevação acentuada na atividade das enzimas antioxidantes em plântulas de alface, afetando o desempenho fisiológico de sementes e o crescimento de plântulas de alface. Palavras-chave: Lactuca sativa, $\alpha$-amilase, pigmentos fotossintéticos, enzimas antioxidantes

\begin{abstract}
The work was conducted to evaluate the effect of different Philodendron bipinnatifidum Schott. extract concentrations on the physiology and enzymatic metabolism of lettuce seeds and seedlings. The treatments extracts of mature leaves at concentrations of $0,6,12,25$ and $50 \%$. Were evaluated the germination, first count germination, speed and germination speed index, length of shoot and primary root, seedling total dry mass, electrical conductivity, chlorophyll content, activity of the enzymes $\alpha$-amilase, superoxide dismutase, catalase and ascorbarto peroxidase, lipid peroxidation, hydrogen peroxide content and seedling emergence, length of shoot and total dry mass of emerged seedlings. There was a reduction of germination, germination speed index and total dry mass by increasing the
\end{abstract}

${ }^{1}$ Parte do Trabalho de Tese de Doutorado do primeiro autor. Trabalho financiado pela CAPES.

${ }^{2}$ Profs. Drs. do Dept ${ }^{\circ}$ de Fitotecnia, Programa de Pós-Graduação em Ciência e Tecnologia de Sementes, Universidade Federal de Pelotas, UFPel, Pelotas, RS. E-mail: tiago.aumonde@gmail.com; francisco.villela@pq.cnpq.br

${ }^{3}$ Bióloga, Dr ${ }^{\mathrm{a}}$, Pós-Doutoranda em Fisiologia Vegetal PNPD-CAPES, Dept ${ }^{\circ}$ de Botânica, UFPel, Pelotas, RS. E-mail: emartinazzo@ gmail.com

${ }^{4}$ Discente de Doutorado, Bolsista CAPES, UFPel, Pelotas, RS. E-mail: tiago.pedo@gmail.com

${ }^{5}$ Profs. Drs. do Dept $^{\circ}$ de Botânica, Programa de Pós-Graduação em Fisiologia Vegetal, UFPel, Pelotas, RS. E-mail: lucianodoamarante@yahoo.com.br; moraesdm@ufpel.edu.br

* Autor para correspondência 
concentration of the extract. While the content of hydrogen peroxide, lipid peroxidation and activity of superoxide dismutase, catalase and peroxidase ascorbarto increased with concentration. The increasing of concentration the leaf extracts of the P. bipinnatifidum negatively affects the activity of the enzyme $\alpha$-amylase and causes increase in the activity of antioxidant enzymes, affecting the physiologic performance and growth of lettuce seedlings.

Key words: Lactuca sativa, $\alpha$-amylase, photosynthetic pigments, antioxidant enzymes

\section{Introdução}

Compostos químicos provenientes do metabolismo secundário vegetal, denominados aleloquímicos, apresentam síntese variável entre espécies, constituido-se reflexo da interação genótipo e ambiente. Os aleloquímicos ao serem liberados por determinado genótipo podem resultar em efeito fitotóxico a outras espécies. Diferentes metabólitos com potencial fitotóxico foram identificados em tecidos de origem vegetal, entre os principais estão os esteróides, fenóis e terpenos, os alcalóides e os taninos, as cumarinas e os flavonóides (PUTNAM; DUKE, 1978).

O nível de fitotoxidez proporcionado é incrementado pelo aumento do período de liberação e pela quantidade de substâncias exsudadas (ALVES; SANTOS, 2002). Estas condições podem resultar na inibição da germinação, redução da velocidade de germinação e do crescimento inicial em resposta ao dano celular ocasionado por alterações na permeabilidade e seletividade de membranas celulares ou por modificações em nível hormonal e fotossintético (ABU-ROMMAN; SHATNAW; SHIBLI,2010; CHOU,2006; HUSSAIN;REIGOSA, 2011). Tais processos constituem resultados da ação dos aleloquímicos, que atuam diretamente, ou na sinalização de processos de degradação celular, por meio da produção e acúmulo de espécies reativas de oxigênio, resultando em estresse oxidativo celular (BOGATEK; GNIAZDOWSKA, 2007; QIAN et al., 2009).

O emprego de espécies indicadoras, em estudos alelopáticos, constitui importante ferramenta para a identificação do potencial tóxico de extratos vegetais. Sementes e plântulas de alface (Lactuca sativa L.) são indicadores eficientes, empregados para a deteç̧ão do efeito alelopático, pela sensibildiade a vários aleloquímicos e a resistência das sementes a ampla faixa de $\mathrm{pH}$ e potencial osmótico (RICE, 1984). Estudos detalhados com vistas à compreensão do efeito do aleloquímico sobre os diferentes processos fisio-metabólicos decorrentes da ação do agente estressor sobre sementes e plântulas são escassos, sendo a resposta do mecanismo enzimático hidrolítico e antioxidativo de sementes e plântulas submetidas a extratos alelopáticos praticamente inexistentes. Enzimas relacionadas à hidrólise do amido atuam na sua degradação com vistas a formação de esqueletos carbônicos voltados à retomada do crescimento do embrião (MARCOS FILHO, 2005), enquanto enzimas do metabolismo antioxidativo são responsáveis pela eliminação de radicais livres formados em tecidos vegetais, sob condições de estresse (GILL; TUTEJA, 2010).

A espécie Philodendron bipinnatifidum é planta da família Araceae, conhecida popularmente como filodendro e empregada com fins ornamentais, cujo gênero apresenta na constituição limonóides, esteróides, isopalmitato e palmitato de etila, além de outros compostos (FEITOSA et al., 2007). Devido aos compostos identificados no gênero da espécie P. bipinnatifidum sua fitotoxidez é provável sobre outros genótipos, sendo importante a elucidação do mecanismo de ação e das respostas fisiológicas da semente e da plântula frente ao estresse imposto. Tal fato pode ser melhor entendido pela avaliação conjunta de diferentes parâmetros empregados rotineriamente na avaliação da qualidade fisiológica de sementes, quantificação da atividade de enzimas envolvidas na degradação do amido e de enzimas antioxidatidantes, responsáveis pela eliminação do peróxido de hidrogênio e de outras espécies reativas de oxigênio que podem atuar na peroxidação lipídica, desencadeando severos danos celulares, paralelamente à quantificação de pigmentos fostossíntéticos. 
Neste contexto, o trabalho foi conduzido com o objetivo de avaliar o efeito de diferentes concentrações do extrato de $P$. bipinnatifidum sobre o desempenho germinativo e o metabolismo enzimático de sementes e plântulas de alface.

\section{Material e Métodos}

O trabalho foi realizado no Laboratório de Fisiologia de Sementes do Departamento de Fitotecnia - Programa de Pós-Graduação em Ciência e Tecnologia de Sementes da Universidade Federal de Pelotas, situada na latitude 3152' S, longitude $52^{\circ} 21^{\prime} \mathrm{W}$ e altitude $13 \mathrm{~m}$. O clima dessa região é temperado, com chuvas bem distribuídas e verão quente, sendo do tipo Cfa pela classificação de Köppen. O solo é classificado como Planossolo e o relevo plano (EMBRAPA, 2006).

O extrato concentrado de plantas de filodendro (P. bipinnatifidum Schott) foi obtido a partir de folhas maduras, completamente expandidas e provenientes de plantas de meia sombra crescidas sob condições de campo. As folhas dotadas de pecíolo carnoso foram previamente lavadas em água destilada e secas com papel toalha. Pela natureza do material com elevada quantidade de água na constituição, as folhas foram trituradas sem adição de tal elemento e centrifugadas em aparelho comercial, onerando o tempo 30 minutos. O extrato obtido, considerado de concentração $100 \%$ foi armazenado em recipiente âmbar sob temperatura de $10{ }^{\circ} \mathrm{C}$, em refrigerador. Após 24 horas, o extrato concentrado foi submetido à filtração simples utilizando papel filtro com gramatura de $80 \mathrm{~g} \mathrm{~m}^{-2}$, espessura de $205 \mu \mathrm{m}$ e maioria dos poros com 14 $\mu \mathrm{m}$, sendo o filtrado armazenado em recipiente âmbar, sob refrigeração a $10^{\circ} \mathrm{C}$. Os tratamentos foram compostos pelas concentrações $0 ; 6 ; 12 ; 25$ e 50\% de extrato de Filodendro, empregando-se a relação $v / v$ entre extrato vegetal e água destilada. Os extratos das diferentes concentrações tiveram o $\mathrm{pH}$ aferido, atingindo 6,0 $\pm 0,1$. Como espécie alvo foram utilizadas sementes de alface cv. Mimosa Salad Bowl ${ }^{\circledR}$.
Para avaliar o efeito das concentrações do referido extrato sobre o desempenho germinativo de sementes e no metabolismo antioxidativo de plântulas foram realizados os seguintes testes:

1- Teste de Germinação (\%): conduzido em quatro repetições com quatro amostras de 50 sementes, semeadas em caixas tipo gerbox, sobre duas folhas de papel mata-borrão umedecidas na proporção de 2,5 vezes a massa do papel seco, com as diferentes concentrações de extrato. Os gerbox foram transferidos para câmara de germinação tipo BOD a $20^{\circ} \mathrm{C}$ e 12 horas de fotoperíodo. As avaliações foram efetuadas aos sete dias após a semeadura e os resultados expressos em porcentagem de plântulas normais, conforme indicado pelas Regras de Análise de Sementes (BRASIL, 2009).

2- Primeira contagem da germinação (\%): realizada conjuntamente ao teste de germinação, aos quatro dias após a semeadura, conforme indicado pelas Regras de Análises de Sementes. Os resultados foram expressos em porcentagem de plântulas normais (BRASIL, 2009).

3- Índice de velocidade de germinação (IVG): obtido a partir de contagens diárias das sementes germinadas (protrusão radicular mínima de 3 a 4 $\mathrm{mm}$ ). As contagens foram realizadas até a obtenção do número constante de sementes germinadas. O IVG foi obtido de acordo com recomendação de Nakagawa (1994).

4- Teor de clorofila $a, b$ e total de plântulas germinadas: a quantificação do teor de clorofila foi efetuada por meio de quatro amostras de 0,2 $\mathrm{g}$ de plântulas por tratamento ao final do teste de germinação, aos sete dias após a semeadura. O material vegetal fresco foi macerado em $10 \mathrm{~mL}$ de acetona $80 \%$ em gral em sala escura, com luz verde. $\mathrm{O}$ macerado foi submetido à filtração simples e o volume de acetona completado para $25 \mathrm{~mL}$, conforme metodologia de Arnon (1949) citada por Falqueto et al. (2009). Os dados obtidos foram expressos em mg de clorofila $\mathrm{g}^{-1}$ massa fresca.

5- Condutividade elétrica (CE): conduzida de acordo com metodologia proposta por 
Krzyzanowski, França-Neto e Henning (1991) conforme Bervald et al. (2010), em quatro repetições com quatro amostras de 50 sementes. As sementes tiveram sua massa previamente aferida e foram submetidas à embebição nos extratos das diferentes concentrações, por 1 hora. Decorrido o tempo, foram lavadas com água destilada, transferidas para recipientes contendo $80 \mathrm{~mL}$ de água deionizada e mantidas em $\mathrm{BOD}$ à temperatura de $20^{\circ} \mathrm{C}$. A condutividade elétrica foi determinada após 3, 6 e 24 horas. Os resultados foram expressos em $\mu \mathrm{S} \mathrm{cm}^{-1}$ $\mathrm{g}^{-1}$ de sementes.

6- Emergência de plântulas em casa de vegetação (\%): conduzido em quatro repetições com quatro amostras de 50 sementes. A semeadura foi efetuada em bandejas de poliestireno expandido de duzentas células, contendo como substrato areia lavada. As sementes foram previamente colocadas entre três folhas de papel germitest umedecido com água destilada em quantidade equivalente a 2,5 vezes a massa do papel por 5 minutos, objetivando evitar dano por embebição. Decorrido o tempo, as sementes foram embebidas nos extratos de diferentes concentrações por uma hora e conduzidas à semeadura. Vinte e um dias após a semeadura foi realizada a contagem final do número de plântulas normais emergidas, sendo os resultados expressos em porcentagem.

7- Comprimento de parte aérea e da raiz primária de plântulas: foram utilizadas quatro repetições com quatro amostras de 10 plântulas, ao final do teste de germinação e de emergência em casa de vegetação, aos 21 dias. O comprimento de parte aérea foi obtido pela distância entre a inserção da porção basal da raiz primária ao ápice da parte aérea, enquanto, o comprimento da raiz primária foi mensurado pela distância entre a parte apical e basal da raiz primária. Os resultados foram expressos em milímetros por plântula (mm plântula ${ }^{-1}$ ).

8- Massa seca total de plântulas: obtidas a partir de quatro sub amostras de 10 plântulas, ao final do teste de germinação e de emergência em casa de vegetação aos 21 dias. As plântulas foram acondicionadas em envelopes de papel pardo e submetidas à secagem em estufa de ventilação forçada sob temperatura de $70{ }^{\circ} \mathrm{C}$ por 72 horas até massa constante. Os resultados foram expressos em miligramas por plântula.

9- Conteúdo de $\mathrm{H}_{2} \mathrm{O}_{2}$ e peroxidação lipídica: foram determinados ao final do teste de germinação por meio de amostras de plântulas maceradas em nitrogênio líquido e homogeneizadas em $2 \mathrm{~mL}$ de ácido tricloroacético (TCA) a $0,1 \%$. O homogenato foi centrifugado a $13.000 \mathrm{~g}$, durante 20 minutos à $4{ }^{\circ} \mathrm{C}$, e o sobrenadante utilizado para determinar o conteúdo de $\mathrm{H}_{2} \mathrm{O}_{2}$ e malondialdeído (MDA). Os níveis de peróxido de hidrogênio foram determinados de acordo com Velikova, Yordanov e Edreva (2000). Em tubos de ensaio contendo $0,7 \mathrm{~mL}$ de tampão fosfato de potássio $10 \mathrm{mM}(\mathrm{pH} \mathrm{7,0)} \mathrm{e} 1 \mathrm{~mL}$ de iodeto de potássio $1 \mathrm{M}$, foram adicionados $0,3 \mathrm{~mL}$ do sobrenadante, e incubado por 10 minutos a $30^{\circ} \mathrm{C}$. As leituras foram efetuadas em espectrofotômetro a $390 \mathrm{~nm}$ e a concentração de $\mathrm{H}_{2} \mathrm{O}_{2}$ expressa em $\mu \mathrm{mol}$ de $\mathrm{H}_{2} \mathrm{O}_{2} \mathrm{~g}^{-1}$ de massa fresca. A peroxidação lipídica foi obtida via acúmulo de MDA e determinada por metodologia descrita por Cakmak e Horst (1991). Em tubos de ensaio contendo 0,3 $\mathrm{mL}$ do sobrenadante foram adicionados $1,7 \mathrm{~mL}$ do meio de reação de ácido tiobarbitúrico (TBA) 0,5\% $(\mathrm{p} / \mathrm{v})$ em TCA $10 \%(\mathrm{p} / \mathrm{v})$, seguido por incubação a $90{ }^{\circ} \mathrm{C}$, por 20 minutos. A reação foi paralisada por resfriamento rápido em gelo e após, centrifugadas novamente a $10.000 \mathrm{~g}$ durante 5 minutos, a $4^{\circ} \mathrm{C}$ e as absorbâncias do sobrenadante determinadas em espectrofotômetro a 535 e $600 \mathrm{~nm}$. A quantidade de complexos MDA-TBA (pigmento vermelho) foi calculado a partir do coeficiente de extinção molar $\left(\varepsilon=155 \times 10^{3} \mathrm{M}^{-1} \mathrm{~cm}^{-1}\right)$.

10- Determinação da enzima $\alpha$-amilase: as extrações foram efetuadas a partir de sementes e também de plântulas provenientes da primeira e da última contagem de germinação (teste de germinação), conforme metodologia descrita pela AOAC, com modificações (SILVA et al., 2008). A maceração do material vegetal foi em gral com 
auxílio de pistilo e com $20 \mathrm{~mL}$ de tampão acetato de potássio $0,1 \mathrm{M}(\mathrm{pH} 5,0)$. O macerado foi centrifugado a $10000 \mathrm{~g}$ por 20 minutos, a $4^{\circ} \mathrm{C}$. O extrato foi vertido para tubos de ensaio e encubado a $70{ }^{\circ} \mathrm{C}$ por 20 minutos, sendo realizada nova centrifugação por 15 minutos. Ao sobrenadante de cada tubo de ensaio adicionou-se $0,5 \mathrm{~mL}$ de extrato, 0,5 mL da solução tampão, $1 \mathrm{~mL}$ de solução de amido e $1 \mathrm{~mL}$ de I2+KI. Os resultados expressos em $\mu \mathrm{g}$ de amido hidrolizado $\min ^{-1} \mathrm{~g}^{-1}$ de massa fresca.

11- Determinação da atividade das enzimas antioxidantes: foram determinadas ao final do teste de germinação, a partir de amostras de matéria fresca de plântulas maceradas em gral e pistilo com nitrogênio líquido, contendo polivinilpolipirrolidona (PVPP) 20\% e homogeneizados em 1,8 mL de tampão fosfato de potássio $100 \mathrm{mM}(\mathrm{pH} 7,8)$ contendo EDTA $0,1 \mathrm{mM}$ e ácido ascórbico $20 \mathrm{mM}$. O extrato foi centrifugado a $13.000 \mathrm{~g}$ por 20 minutos a $4{ }^{\circ} \mathrm{C}$ e o sobrenadante utilizado para mensurar a atividade enzimática.

11.1- Superóxido dismutase (SOD - EC 1.15.1.1): a atividade foi avaliada pela capacidade da enzima inibir a fotorredução do azul de nitrotetrazólio (NBT) a $560 \mathrm{~nm}$ em meio de reação contendo tampão fosfato de potássio $50 \mathrm{mM}(\mathrm{pH}$ 7,8), metionina $14 \mathrm{mM}$, EDTA $0,1 \mu \mathrm{M}$, NBT 75 $\mu \mathrm{M}$ e riboflavina $2 \mu \mathrm{M}$ conforme Giannopolitis e Ries (1977). Uma unidade de atividade da SOD foi definida como a quantidade de enzima que produz uma inibição de $50 \%$ da redução fotoquímica do NBT.

11.2- Catalase (CAT - EC 1.11.1.6): determinada conforme descrito por Azevedo et al. (1998). A atividade foi monitorada pelo decréscimo na absorbância a $240 \mathrm{~nm}\left(\varepsilon=39.4 \times 10^{3} \mathrm{M}^{-1} \mathrm{~cm}^{-1}\right)$, durante 2 min em meio de reação de $4 \mathrm{~mL}$ incubado a $30{ }^{\circ} \mathrm{C}$, contendo extrato enzimático, tampão fosfato de potássio $100 \mathrm{mM}(\mathrm{pH} 7,0)$ e peróxido de hidrogênio $12,5 \mathrm{mM}$.

11.3- Ascorbato peroxidase (APX - EC 1.11.1.11): determinada por metodologia proposta por Nakano e Asada (1981) pelo monitoramento da taxa de oxidação do ascorbato (ASA) por 2 min a $290 \mathrm{~nm}\left(\varepsilon=2.80 \times 10^{3} \mathrm{M}^{-1} \mathrm{~cm}^{-1}\right)$. O meio de reação foi incubado a $30^{\circ} \mathrm{C}$ e composto por tampão fosfato de potássio $100 \mathrm{mM}(\mathrm{pH} 7,0)$ ácido ascórbico 0,5 $\mathrm{mM}, \mathrm{H}_{2} \mathrm{O}_{2} 0,1 \mathrm{mM}$ e extrato enzimático.

O delineamento experimental foi de blocos casualizados com quatro repetições. Os dados foram submetidos à análise de variância e havendo significância a $5 \%$, foram ajustados por polinômios ortogonais.

\section{Resultados e Discussão}

A germinação de sementes de alface apresentou redução com o aumento da concentração do extrato de P. bipinnatifidum (Figura 1a). Este fato pode ser explicado pela menor sensibilidade do processo germinativo aos aleloquímicos ou a baixa toxidez dos compostos, comparativamente ao crescimento inicial (ZHANG et al., 2010). Por outro lado, ocorreu redução acentuada na germinação a partir da concentração $12 \%$, sendo as concentrações 25 e 50\% (ponto de mínima) responsáveis pela diminuição do número de plântulas normais em mais de $80 \%$ e $90 \%$, respectivamente. A diminuição da germinação indica que o processo germinativo foi influenciado negativamente pelo aumento na concentração do extrato, o que pode estar associado ao acúmulo de formas reativas de oxigênio e aumento da peroxidação lipídica em plântulas (Figura 3b e 3c). Além disso, pode ser também evidenciado em sementes, pelo aumento da condutividade elétrica (Figura 2b). Estes processos, possivelmente, possuem estreita relação com o efeito tóxico dos limonóides, esteróides, isopalmitato e palmitato de etila, conforme relatado por Feitosa et al. (2007) para espécies do gênero $P$. bipinnatifidum. Redução da germinação de sementes de Parthenium hysterophorus foi abservada por Wakjira, Berecha e Bulti (2011), após submissão a extratos de Albizia gummifera, Melia azedarach e Sesbania sesban. 
Figura 1. Germinação $(\mathrm{G})$ e primeira contagem de germinação (PC) (a), índice de velocidade de germinação (b) de sementes de alface sob ação de concentrações do extrato de P. bipinnatifidum (significativo a 5\% *).
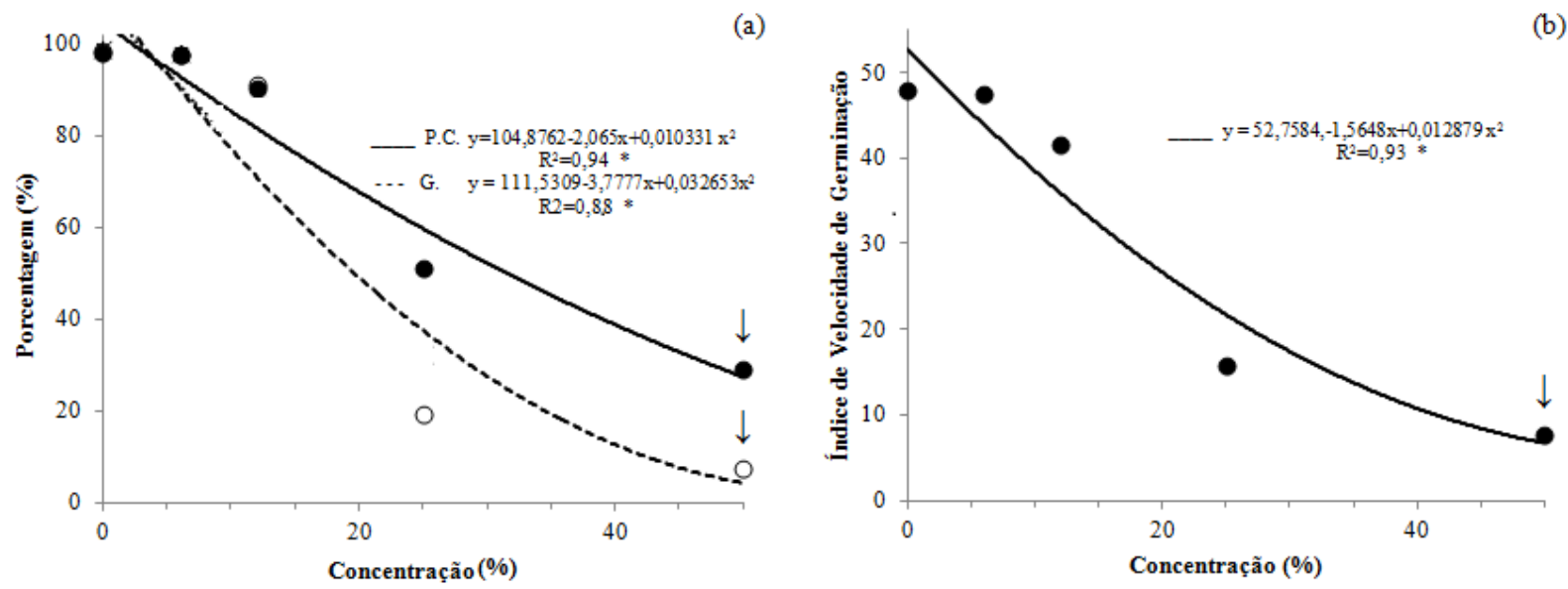

Fonte: Elaboração dos autores.

A primeira contagem de germinação mostrou decréscimo com o aumento da concentração do extrato (Figura 1a), ocorrendo semelhança entre os valores da primeira contagem de germinação nas concentrações 0 e $6 \%$ que mantiveram número de sementes germinadas similar às do teste de germinação (Figura 1a). Por outro lado, a partir da concentração $12 \%$ que proporcionou redução de $10 \%$ na germinação, houve tendência de inibição drástica deste processo fisiológico até as concentrações 25 e $50 \%$ (ponto de mínima), sendo que o número total de sementes germinadas atingiu valores 50 e $80 \%$ abaixo da concentração zero. É possível verificar que a primeira contagem de germinação não demonstrou alterações na capacidade germinativa de sementes nas baixas concentrações do extrato, necessitando a elevação da concentração acima de $12 \%$ para proporcionar efeito prejudicial. Desse modo, o efeito tóxico de determinado extrato vegetal depende da concentração dos compostos tóxicos e do tecido de extração (WU et al., 2009), o que em parte, explica a redução da germinação nas maiores concentrações do extrato.
O índice de velocidade de germinação ajustouse a uma equação quadrática e, decresceu com o aumento da concentração do extrato, porém foi afetado de forma mais marcante a partir da concentração de $12 \%$, atingindo o ponto de mínima na concentração de $50 \%$ (Figura $1 \mathrm{~b}$ ). Tal processo pode ser relacionado ao efeito negativo do extrato sobre a mobilização de reservas para o embrião, frente à exacerbada atividade da enzima $\alpha$-amilase na semente (Figura 3a). Além disso, pode ser devido à redução da atividade da $\alpha$-amilase em plântulas submetidas a concentrações mais elevadas do extrato na primeira contagem de germinação (Figura 3a). Fase na qual, a conversão de amido em açúcares passíveis de utilização pelo embrião deveria ser máxima, objetivando a retomada do seu crescimento. Neste contexto, é possível que tenha ocorrido à lixiviação e não absorção da grande maioria das moléculas sintetizadas a partir da hidrólise do amido pelo embrião, o que é explicado pela despolarização e redução da capacidade seletiva do sistema de membranas celulares (Figura 2b). 
Figura 2. Teor de clorofila $a, b$ e total de plântulas germinadas (a), condutividade elétrica de sementes (b), comprimento de parte aérea $(\mathrm{CPA})$ e da raiz primária $(\mathrm{CPR})$ de plântulas germinadas (c), emergência de plântulas em casa de vegetação (d), comprimento de parte aérea (CPA) e da raiz primária (CPR) de plântulas emergidas (e) e massa seca total de plântulas de alface (f) sob ação de concentrações do extrato de P. bipinnatifidum (significativo a 5\%*).
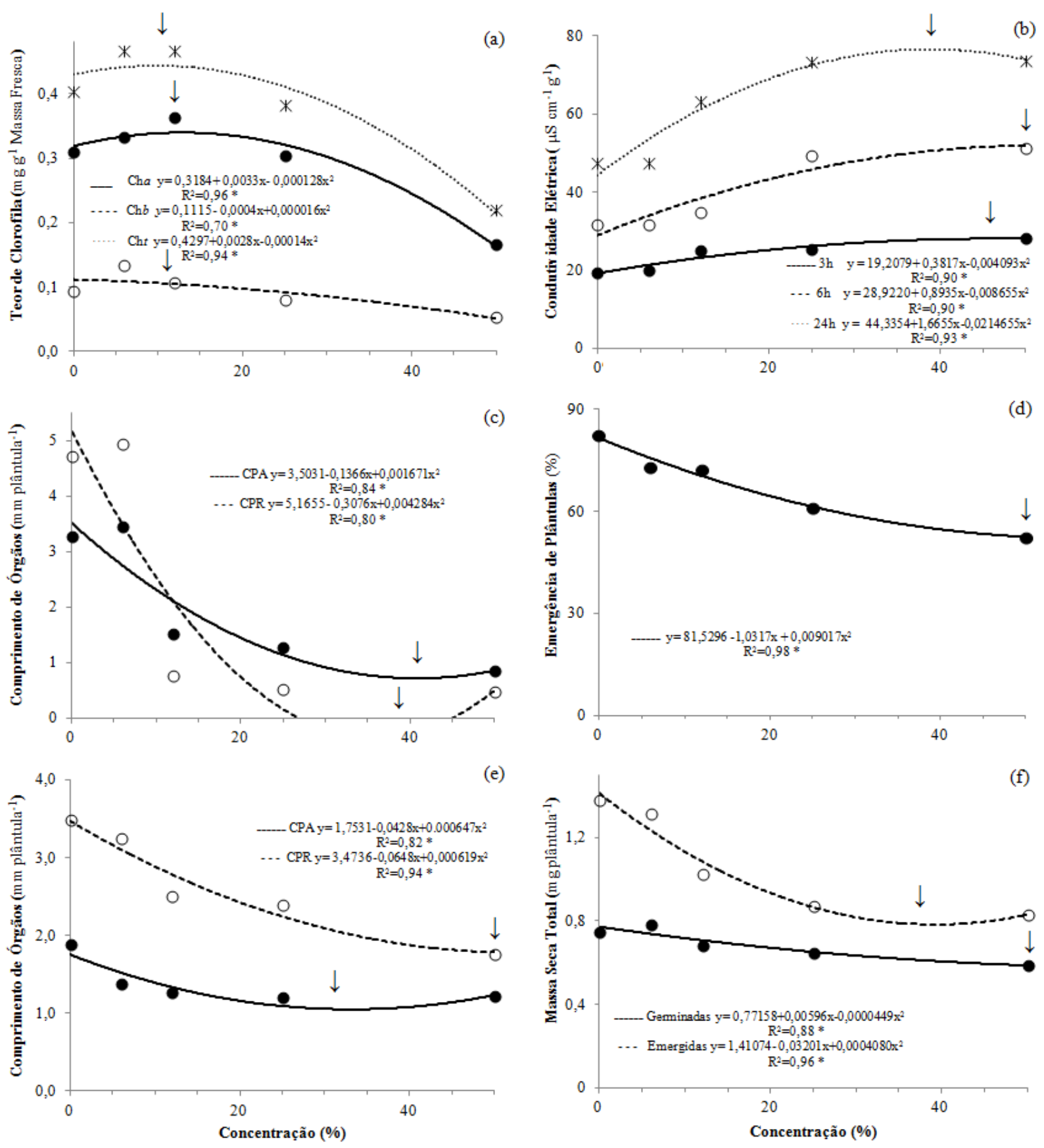

Fonte: Elaboração dos autores. 
Figura 3. Atividade da enzima $\alpha$-amilase: semente, primeira contagem (PC) e teste de germinação (UC) de plântulas germinação (a), peróxido de hidrogênio (b), peroxidação lipídica (c), atividade das enzimas: superóxido-dismutase SOD (d), catalase - CAT (e), ascorbato-peroxidase - APX (f), em plântulas de alface obtidas em laboratório sob ação de concentrações do extrato de P. bipinnatifidum (significativo a $5 \%$ *).
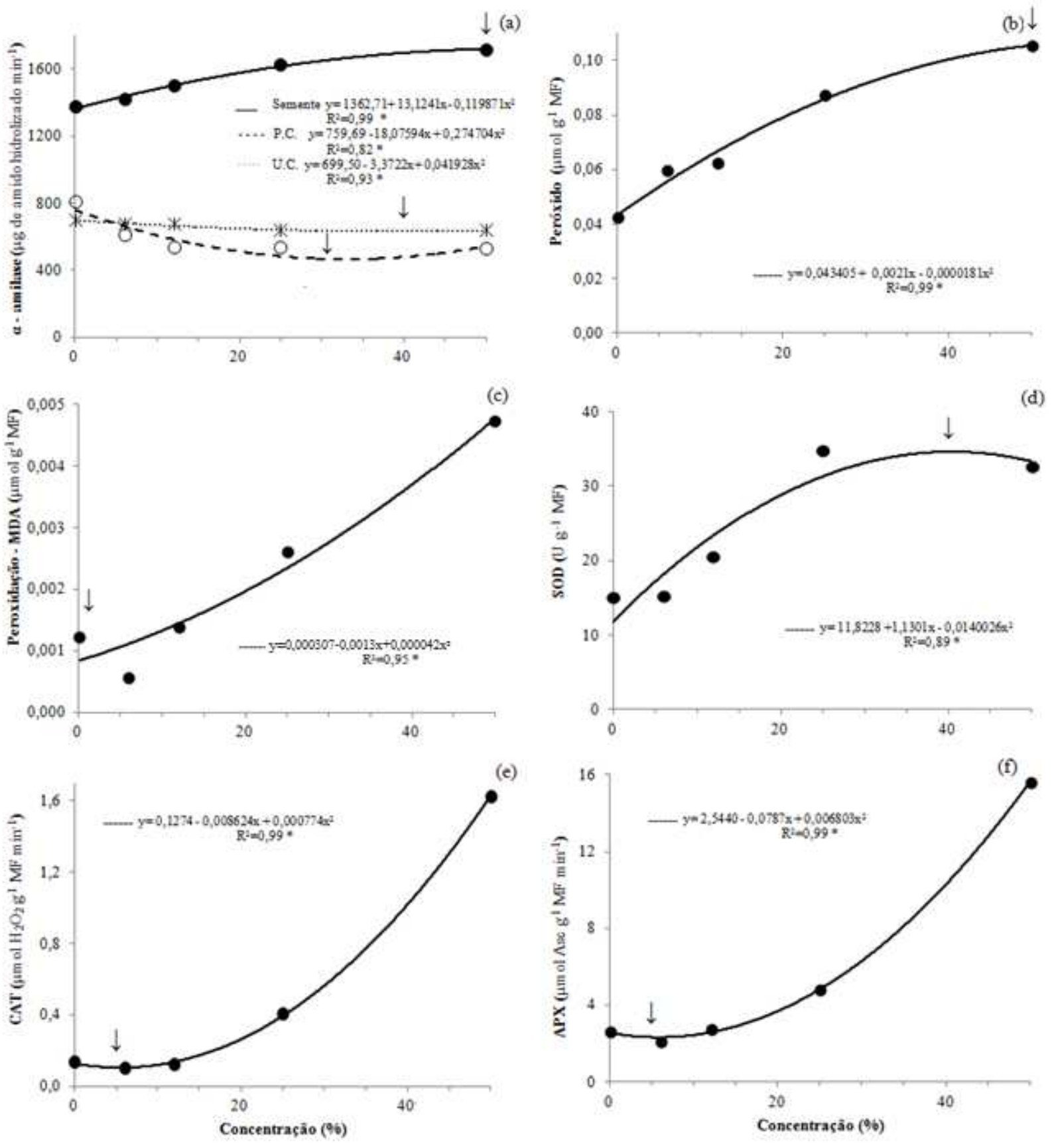

Fonte: Elaboração dos autores.

Os teores de clorofila foram alterados pelo incremento da concentração do extrato (Figura 2a). As clorofilas a (ponto de máxima de $12,89 \%$ ) e $b$ (ponto de máxima de 12,50\%) mostraram tendência ao aumento até a concentração $12 \%$. $\mathrm{O}$ aumento da clorofila $b$ pode ser relacionado à tentativa de aclimatação da espécie, devido sua função fotoprotetora (MARENCO; LOPES, 2005). 
A partir da concentração $12 \%$ houve decréscimo conjunto nos teores de clorofila $a$ e $b$, sendo possível inferir que o aumento da concentração do extrato afetou quali-quantitativamente o teor de pigmentos fotossintéticos e colaborou para a redução do teor de clorofila total (ponto de máxima de 11,67\%). Tal ocorrência mantém relação ao fato de compostos tóxicos ou aleloquímicos interferirem na fotossíntese, pela alteração no teor de clorofila em processos envolvendo enzimas clorofilases, por influenciar negativamente a eficiência do fotossistema II reduzido a absorção de fótons pelo sistema antena (HUSSAIN; REIGOSA, 2011) ou ainda pela inibição da síntese de precursores da porfirina (RICE, 1984), um constituinte da clorofila. Ao estudarem o potencial alelopático do óleo volátil de Eucalyptus tereticornis sobre Amaranthus viridis, Kaur et al. (2011) obtiveram redução dos teores de clorofila $a$ e $b$.

A condutividade elétrica ajustou-se ao modelo quadrático com elevado coeficiente de determinação e aumentou nos três tempos de incubação, indicando que indiferentemente ao tempo houve em relação à concentração zero, tendência ao aumento na liberação de eletrólitos com a elevação da concentração do extrato. Para 3 e 6 horas o ponto de máxima foi atingido em $50 \%$ e para 24 horas em 38,60\% (Figura 2b). O processo de liberação acentuada de eletrólitos é explicado pela danificação ao sistema de membranas celulares da semente e corrobora ao acúmulo de peróxido de hidrogênio e à elevação da peroxidação lipídica em plântulas de alface, frente ao estresse promovido pelo aumento da concentração do extrato (Figura 3a e 3b).

O comprimento de parte aérea e de raiz primária, em plântulas emergidas, mostrou decréscimo ao aumentar a concentração do extrato (Figura 2c e 2e). Em plântulas provenientes do teste de germinação houve redução superior a $90 \%$ no comprimento da raiz primária (ponto de mínima de $38,75 \%$ ) e a $74 \%$ no comprimento de parte aérea (ponto de mínima de 41,18\%), enquanto, plântulas emergidas do substrato em casa de vegetação obtiveram comprimento da raiz primária (ponto de mínima de 50\%) reduzido em cerca de $49 \%$ e o de parte aérea (ponto de mínima de 33,07\%) superior a 36\%. Sob condições laboratoriais, o extrato proporcionou aos órgãos da plântula maior fitotoxidez com o incremento da concentração do extrato, comparativamente àquelas emergidas. A diferença marcante na fitotoxidez sobre o crescimento de parte aérea e raiz primária é devida ao fato do ambiente laboratorial favorecer a germinação e o crescimento. Esta condição, provavelmente, beneficiou a absorção e a translocação dos compostos presentes no extrato para os diferentes órgãos da plântula e resultou na redução drástica de parte aérea e de raiz nestas circunstâncias.

Todavia, o maior período de contato e a exposição direta da raiz primária a ação do extrato pode ter colaborado para a maior redução do comprimento deste órgão em relação à parte aérea (ALVES; SANTOS, 2002; DAILIRI et al., 2011). Além disso, segundo Alves e Santos (2002), a alteração no comprimento de órgãos da plântula está relacionada à modificação no balanço hormonal do vegetal. Ao estudarem o efeito de óleos voláteis de alecrimpimenta, Alves et al. (2004) observaram redução proporcional da raiz ao aumentar a concentração do extrato. Por outro lado, Maraschin-Silva e Aqüila (2006) observaram que extratos de Psychotria leiocarpa reduziram o comprimento de parte aérea de plântulas de alface. Manoel et al. (2009), verificaram que plântulas de tomateiro sob ação das concentrações 50 e $75 \%$ de extrato aquoso de Stryphnodendron adstringens apresentam drástica redução no comprimento médio da raiz.

A massa seca total de plântulas obtidas em laboratório e emergidas em casa de vegetação mostrou redução com o incremento da concentração do extrato de P. bipinnatifidum (Figura 2f). Houve redução superior a 39 e $21 \%$ respectivamente na massa seca de plântulas obtidas em laboratório (ponto de mínima de 50\%) e em casa de vegetação (ponto de mínima de 37,50\%). A redução da massa seca das plântulas foi ocasionada em parte, pelo menor comprimento de órgãos (Figura 2c e 2e) e possivelmente esteja associada ao colapso 
do sistema hidrolítico (Figura 3a) e da rede interligada de membranas celulares (Figura 2b). Tais processos constituem reflexo da elevação na produção e acúmulo de radicais livres (Figura $3 b$ ), que indiretamente podem ter influenciado negativamente à translocação e alocação de assimilados para a plântula por afetarem a atividade da enzima $\alpha$-amilase. Tal hipótese corrobora as afirmações de Muniz et al. (2007) ao relatarem que a inibição da enzima $\alpha$-amilase ocorre na presença de determinados compostos químicos vegetais, podendo ser efeito indireto da inibição na síntese de ácido giberélico (POLITYCKA; GMEREK, 2008).

A emergência em casa de vegetação apresentou decréscimo ao se aumentar à concentração do extrato (ponto de mínima de 50\%), sendo os resultados mais expressivos obtidos a partir da concentração $12 \%$ (Figura 2d). Ao submeter sementes às concentrações $12 ; 25$ e $50 \%$ houve, em relação à concentração zero, redução de $12 ; 26$ e 36\% respectivamente no número de plântulas emergidas. Neste contexto, o extrato de $P$. bipinnatifidum afetou drasticamente o vigor de sementes de alface, processo que demonstra estreita relação com a danificação de membranas celulares e é evidenciado pelo aumento da condutividade elétrica em sementes (Figura 2b) e pela elevação da peroxidação lipídica em plântulas (Figura 3b). De maneira similar, Santos et al. (2002) obtiveram redução na emergência de plântulas de caruru-demancha frente ao aumento da concentração do extrato de casca de arroz.

$\mathrm{O}$ acúmulo de peróxido de hidrogênio ajustouse ao modelo quadrático e apresentou aumento com a elevação da concentração do extrato (ponto de máxima de 50\%), processo que colaborou para a elevação da peroxidação lipídica (ponto de mínima de 1,55\%) (Figura $3 b$ e $3 c$ ) e para a redução do número de plântulas normais (Figura 1a). O aumento da concentração de peróxido de hidrogênio no meio extracelular pode induzir o acréscimo na permeabilidade dos canais de cálcio, consequentemente, elevar a concentração de cálcio livre no citosol (MORI; SCHROEDER, 2004) e alterar diferentes processos fisiológicos.
A atividade das enzimas superóxido dismutase (ponto de máxima de 40,40\%), catalase (ponto de mínima de 5,50\%) e ascorbato-peroxidase (ponto de mínima de 5,78\%) foi incrementada pelo aumento da concentração do extrato (Figura 3d, 3e e 3f), que entre outros fatores, também pode ser reflexo da elevação da quantidade de peróxido de hidrogênio (Figura 3b). A atividade da SOD apresentou tendência acentuada de aumento a partir da concentração $12 \%$ e a atividade as enzimas CAT e APX a partir da concentração $25 \%$. Neste contexto, o incremento da atividade antioxidante da enzima superóxido-dismutase ocorreu provavelmente em resposta à elevação da quantidade de radicais superóxido $\left(\mathrm{O}_{2}{ }^{\bullet}\right)$ produzidos pelo bloqueio da cadeia de transporte de elétrons, conjuntamente à geração de elétrons livres ou pela reação de transferência de elétrons do NAPH para o oxigênio molecular. A conversão do radical $\mathrm{O}_{2}{ }^{\bullet-}$ mediada pela enzima SOD proporcionou a formação de peróxido de hidrogênio (SINHA; SAXENA, 2006), composto que pode ocasionar estresse oxidativo. Frente à elevação dos níveis de peróxido de hidrogênio, a enzima catalase foi induzida e ao atuar em conjunto com a ascorbato-peroxidase possivelmente degradou, até certo ponto, o peróxido de hidrogênio em água oriundo da reação catalisada pela SOD e ainda, em água e oxigênio molecular naquela mediada pela APX (BARREIROS; DAVID; DAVID, 2006). Cabe salientar que, mesmo com a elevação acentuada na atividade das enzimas antioxidativas, ocorreu aumento da concentração do extrato, elevação na produção de peróxido de hidrogênio e da peroxidação lipídica afetando a integridade do sistema de membranas celulares, conforme evidenciado em sementes pelo aumento da condutividade elétrica (Figura 2b) e em plântulas pela redução do número de plântulas normais, diminuindo a germinação (Figura 1a). Tal ocorrência evidencia a ineficiência destas enzimas no processo de detoxificação dos tecidos da plântula ao ser submetida às maiores concentrações do extrato de $P$. bipinnatifidum. 
Uma análise conjunta dos resultados alcançados permite constatar que concentrações do extrato de folhas maduras de $P$. bipinnatifidum compreendidas entre $25 \%$ até $50 \%$ afetaram de modo prejudicial o desempenho germinativo de sementes de alface, inclusive os fatores de crescimento de plântulas. Além disso, houve alteração na atividade enzimática, indicativo do processo de deterioração de sementes de alface.

\section{Conclusões}

O aumento da concentração do extrato de folhas de $P$. bipinnatifidum afeta negativamente a atividade da enzima $\alpha$-amilase e provoca elevação acentuada na atividade das enzimas antioxidantes em plântulas de alface, afetando o desempenho fisiológico de sementes e o crescimento de plântulas de alface.

\section{Referências}

ABU-ROMMAN, S.; SHATNAWI, M.; SHIBLI, R. Allelopathic Effects of spurge (Euphorbia hierosolymitana) on wheat (Triticum durum). AmericanEurasian Journal of Agricultural \& Environmental Sciences, Dubai, v. 7, n. 3, p. 298-302, 2010.

ALVES, M. C. S.; MEDEIROS FILHO, S.; INNECCO, R.; TORRES, S. B. Alelopatia de extratos voláteis na germinação de sementes e no comprimento da raiz de alface. Pesquisa Agropecuária Brasileira, Brasília, v. 39, n. 11, p. 1083-1086, 2004.

ALVES, S. M.; SANTOS, L. S. Natureza química dos agentes alelopáticos. In: SOUZA FILHO, A. P. S.; ALVES, S. M. (Ed.). Alelopatia: princípios básicos e aspectos gerais. Belém: Embrapa Amazônia Oriental, 2002. p. 25-47.

AZEVEDO, R. A.; ALAS, R. M.; SMITH, R. J.; LEA, P. J. Response from elevated carbon dioxide to air and ozone fumigation in leaves and roots of wild type and a catalase-deficient mutant of barley. Physiologia Plantarum, Blacksburg, v. 104, n. 2, p. 280-292, 1998.

BARREIROS, A. L. B. S.; DAVID, J. M.; DAVID, J. P. Estresse oxidativo: relação entre geração de espécies reativas e defesa do organismo. Química Nova, São Paulo, v. 29, n. 1, p. 113-123, 2006.
BERVALD, C. M. P.; MENDES, C. R.; TIMM, F. C.; MORAES, D. M.; BARROS, A. C. S. A.; PESKE, S. T. Desempenho fisiológico de sementes de soja de cultivares convencional e transgênica submetidas ao glifosato. Revista Brasileira de Sementes, Brasília, v. 32, n. 2, p. 9-18, 2010.

BOGATEK, R.; GNIAZDOWSKA, A. ROS and phytohormones in plant-plant allelopathic Interaction. Plant Signaling \& Behavior, Austin, v. 2, n. 4, p. 317318, 2007.

BRASIL. Ministério da Agricultura e Reforma Agrária. Regras para análise de sementes. Brasília: SNAD/ CLAV, 2009. 398 p.

CAKMAK, I.; HORST, W. J. Effect of aluminium on lipid peroxidation, superoxide dismutase, catalase, and peroxidase activities in root tips of soybean (Glycine max). Physiologia Plantarum, Copenhagen, v. 83, n. 3, p. 463-468, 1991.

CHOU, C. H. Introduction to allelopathy. In: REIGOSA, M. J.; PEDROL, N.; GONZÁLEZ, L. (Ed.). Allelopathy: a physiological process with ecological implications. Dordrecht: Springer. 2006. 637 p.

DAILIRI, M. S.; MAZLOOM, P.; TOUDAR, S.; ABOLFATHI, H. Inhibitive effects of barley on germintation and growth of seedling thorn-apple. American-Eurasian Journal of Agricultural \& Enviromental Sciences, Dubai, v. 10, n. 6, p. 1000010005, 2011.

EMPRESA BRASILEIRA DE PESQUISA AGROPECUÁRIA - EMBRAPA. Sistema brasileiro de classificação de solos. 2. ed. Rio de janeiro: Embrapa, 2006. 306 p.

FALQUETO, A. R.; CASSOL, D.; MAGALHÃES JUNIOR, A. M.; OLIVEIRA, A. C.; BACARIN, M. A. Physiological analysis of leaf senescence of two rice cultivars with different yield potential. Pesquisa Agropecuária Brasileira, Brasília, v. 44, n. 7, p. 695-700, 2009.

FEITOSA, C. M.; BEZERRA, M. Z. B.; CITÓ, A. M. G. L.; COSTA JUNIOR, J. S.; LOPES, J. A. D.; IOTA NETO, J. M. Constituintes químicos de Philodendron imbé Schott. Química Nova, São Paulo, v. 30, n. 1, p. 41-44, 2007.

GIANNOPOLITIS, C. N.; RIES, S. K. Superoxide dismutase. I. Occurrence in higher plants. Plant Physiology, Illinois, v. 59, n. 2, p. 309-314, 1977.

GILL, S. S.; TUTEJA, N. Reactive oxygen species and antioxidant machin ery in abiotic stress tolerance in crop plants. Plant Physiolog y and Biochemistry, New Delhi, v. 48, n. 12, p. 909-930, 2010. 
HUSSAIN, M. I.; REIGOSA, M. J. Allelochemical stress inhibits growth, leaf water relations, PSII photochemistry, non-photochemical fluorescence quenching, and heat energy dissipation in three C3 perennial species. Journal of Experimental Botany, Oxford, v. 62, n. 13, p. 4534545, 2011.

KAUR, S.; SINGH, H. P.; BATISH, D. R.; KOHLI, R. K. Chemical characterization and allelopathic potential of volatile oil of Eucalyptus tereticornis against Amaranthus viridis. Journal of Plant Interactions, London, v. 6, n. 4, p. 297-302, 2011.

KRZYZANOWSKI, F. C.; FRANÇA-NETO, J. B.; HENNING, A. A. Relato dos testes de vigor disponíveis para grandes culturas. Informativo ABRATES, Brasília, v. 1, n. 2, p. 15-50, 1991.

MANOEL, D. D.; DOICHE, C. F. R.; FERRARI, T. B.; FERREIRA, G. Atividade alelopática dos extratos fresco e seco de folhas de barbatimão (Stryphnodendron adstringens (Mart.) Coville) e pata-de-vaca (Bauhinia forficata Link) sobre a germinação e desenvolvimento inicial de plântulas de tomate. Semina: Ciências Agrárias, Londrina, v. 30, n. 1, p. 63-70, 2009.

MARASCHIN-SILVA, F.; AQÜILA, M. E. A. Potencial alelopático de espécies nativas na germinação e crescimento inicial de Lactuca sativa L. Acta Botânica Brasílica, Feira de Santana, v. 20, n. 1, p. 61-69, 2006.

MARCOS FILHO, J. Fisiologia de sementes de plantas cultivadas. Piracicaba: Fealq, 2005. 495 p.

MARENCO, R. A.; LOPES, N. F. Fisiologia vegetal: fotossíntese, respiração, relações hídricas e nutrição mineral. 2. ed. Viçosa: UFV, 2005. 451 p.

MORI, I. C.; SCHOROEDER, J. I. Reactive oxygen species activation of plant $\mathrm{Ca}^{2+}$ channels. A signaling mechanism in polar growth, hormone transduction, stress signaling, and hypothetically mechanotransduction. Plant Physiology, Washington, v. 135, n. 2, p. 702-708, 2004.

MUNIZ, F. R.; CARDOSO, M. G.; VON PINHO, E. V. R.; VILLELA, M. Qualidade fisiológica de sementes de milho, feijão, soja e alface na presença de extrato de tiririca. Revista Brasileira de Sementes, Brasília, v. 29, n. 2, p. 195-204, 2007.

NAKAGAWA, J. Testes e vigor baseados na avaliação de plântulas. In: VIEIRA, R. D.; CARVALHO, N. M. (Ed.). Testes de vigor em sementes. Jaboticabal: FUNEP, 1994, p. 49-85.

NAKANO, Y.; ASADA, K. Hydrogen peroxide is scavenged by ascobate-specific peroxidase in spinach chloroplasts. Plant and Cell Physiology, Kyoto, v. 22, n. 5, p. 867-880, 1981.
POLITYCKA, B.; GMEREK, J. Effect of ferulic and p-coumaric acidson the activity of hydrolytic enzymes and growth of radicals in germinating seeds of cucumber and pea. Allelopathy Journal, Haryana, v. 21, n. 2, p. 227-238, 2008.

PUTNAM, A. R.; DUKE, W. B. Allelopathy in Agroecosystems. Annual Review of Phytopathology, Palo Alto, v. 16, n. 1, p. 431-451, 1978.

QIAN, H.; XU, X.; CHEN, W.; JIANG, H.; JIN, Y.; LIU, W. Allelochemical stress causes oxidative damage and inhibition of photosynthesis in Chlorella vulgaris. Chemosphere, Oxford, v. 75, n. 3, p. 368-375, 2009.

RICE, E. L. Allelopathy. 2. ed. Academic Press: New York, 1984. 422 p.

SANTOS, J. C. F.; SOUZA, I. F.; MENDES, A. N. G.; MORAIS, A. R.; CONCEIÇÃO, H. E. O.; MARINHO, J. T. S. Efeito de extratos de cascas de café e de arroz na emergência e no crescimento do caruru-de-mancha. Pesquisa Agropecuária Brasileira, Brasília, v. 37, n. 6, p. 783-790, 2002.

SILVA, R. N.; DUARTE, G. L.; LOPES, N. F.; MORAES, D. M.; PEREIRA, A. L. A. Composição química de sementes de trigo (Triticum aestivum L.) submetidas a estresse salino na germinação. Revista Brasileira de Sementes, Brasília, v. 30, n. 1, p. 215-220, 2008.

SINHA, S.; SAXENA, R. Effect of iron on lipid peroxidation, and enzymatic and nonenzymatic antioxidants and bacoside-a content in medicinal plant bacopa monnieri 1. Chemosphere, Oxford, v. 62, n. 8, p. 1340-1350, 2006.

VELIKOVA, V.; YORDANOV, I.; EDREVA, A. Oxidative stress and some antioxidant systems in acid rain-treated bean plants. Plant Science, Limerick, v. 151, n. 1, p. 59-66, 2000.

WAKJIRA, M.; BERECHA, G.; BULTI, B. Phytotoxic effects of multi-purpose tree species on germination and growth Parthenium hysterophorus L. International Journal of Agricultural Research, Lagos, v. 6, n. 2, p. 149-162, 2011.

WU, A. P.; YU, H.; GAO, S. Q.; HUANG, Z. Y.; HE, W. M.; MIAO, S. L.; DONG, M. Differential belowground allelopathic effects of leaf and root of Mikania micrantha. Trees Structure and Function, Berlin, v. 23, n. 1, p. 1117, 2009.

ZHANG, D.; ZHANG, J.; YANG, W.; WU, F. Potential allelopathic effect of Eucalyptus grandis across a range of plantation ages. Ecological Research, Tsukuba, v. 25, n. 1, p. 13-23, 2010. 